\title{
David Oliver: Do bed and chair sensors really stop falls in hospital?
}

\section{David Oliver consultant in geriatrics and acute general medicine}

Berkshire

In December a coroner's narrative verdict was widely covered in the media. "Frail hospital patients put at risk for want of basic equipment costing less than $£ 100$, coroner warns," reported the Telegraph. ${ }^{1}$ The verdict concerned Ken Swift, 80, a retired nurse who had been admitted to York Hospital with pneumonia. He fell from his hospital bed and sustained a hip fracture, which the coroner said was likely to have contributed to his death.

Bed and chair sensors had been recommended as part of Swift's care plan. These devices trigger an alarm or warning light if patients leave their bed or chair for a few seconds. Staff can then, in theory, respond quickly and intervene to prevent a fall or assist the patient. Maybe the alarm reminds the patient (if not too confused) to sit back down or alerts visitors or other patients in the ward bay. The coroner noted that such devices cost under $£ 90$, that over 30 of the hospital's patients were on a waiting list for one, but that the hospital didn't have enough sensors.

Clinical trials give us a considerable evidence base around interventions to prevent falls in institutional settings, set out clearly by the Cochrane Collaboration, ${ }^{2}$ the National Institute for Health and Care Excellence, ${ }^{3}$ and detailed evidence commentaries. ${ }^{4}$ What emerges is that, in trials, even multi-pronged approaches to preventing falls will reduce them by around $20 \%$ at best. Trials are rarely powered sufficiently to detect reductions in serious injuries such as fractures, even when pooled for meta-analysis. They rarely incorporate balancing measures around potential harms from immobility and loss of function.

If we look specifically at evidence from clinical trials of bed and chair sensors and fall alarms we find only very weak evidence that such sensors work at population level, even if some staff or individuals at risk may be helped or reassured by them..$^{5-7}$ The routine use of sensors isn't recommended in good practice guidance. $^{89}$

We should also consider their downsides. For many patients who have dementia or incident delirium, having an alarm sound every time they try to leave their bed or chair could worsen their distress and disorientation and could be considered a form of restraint. Alarms are also unsettling for patients in other beds-adding to noise pollution, poor sleep, and their own risk of delirium. If we're trying to improve patients' independence after acute illness or injury, sensors could actually worsen the cycle of immobility and deconditioning.

We can't engineer falls, or the risk of them, from systems. Their occurrence doesn't automatically represent poor care

We can look outside the evidence from randomised clinical trials, with pre-specified intervention protocols and time limited interventions. Some examples of pragmatic quality improvement approaches are promising, such as "safety huddles" or care bundles, where interventions are refined and implemented through "plan-do-study-act-evaluate" cycles. ${ }^{10}{ }^{11}$ I totally support such pragmatic approaches, although we still need to look at the opportunity cost from focusing excessively on fall prevention.

Falls and subsequent injuries will happen among older, frailer people admitted to hospitals and living in care homes-many with cognitive or sensory impairment, previous falls, impaired gait, muscle strength and balance problems, acute intercurrent illness, faints, or dizziness. We can't engineer falls, or the risk of them, from systems. Their occurrence doesn't automatically represent poor care. Hospitals or care homes are no more "places of safety" than being back at home.

Marketing materials from companies that manufacture sensors are not credible evidence. And coroners should have a basic grasp of research evidence before making controversial pronouncements.

Competing interests: See www.bmj.com/about-bmj/freelancecontributors/david-oliver.

Provenance and peer review: Commissioned; not externally peer reviewed.

Follow David on Twitter: @mancunianmedic 
1 Donnelly L, Moore A. Frail hospital patients put at risk for want of basic NHS equipment costing less than $£ 100$, coroner warns. Telegraph 23 Dec 2017. www.telegraph.co.uk/ news/2017/12/23/rrail-hospital-patients-put-risk-want-basic-nhs-equipment-costing/.

2 Cameron ID, Gillespie LD, Robertson MC. Interventions for preventing falls in older people in care facilities and hospitals. Cochrane Database Syst Rev 2012;12:CD005465. http:// onlinelibrary.wiley.com/doi/10.1002/14651858.CD005465.pub3/full.23235623

3 National Institute for Health and Care Excellence. Falls in older people: assessing risk and prevention. June 2013. https://www.nice.org.uk/Guidance/CG161.

4 Oliver D, Healey F, Haines TP. Preventing falls and fall-related injuries in hospitals. Clin Geriatr Med 2010;26:645-92. http://www.geriatric.theclinics.com/article/S0749-0690(10) 00053-4/abstract. doi:10.1016/j.cger.2010.06.00520934615

5 Sahota O, Drummond A, Kendrick D. REFINE (REducing Falls in In-patieNt Elderly) using bed and bedside chair pressure sensors linked to radio-pagers in acute hospital care: a randomised controlled trial. Age Ageing 2014;43:247-53. doi:10.1093/ageing/aft155. https: //www.ncbi.nlm.nih.gov/pubmed/24141253.24141253

6 Shorr RI, Chandler AM, Mion LC. Effects of an intervention to increase bed alarm use to prevent falls in hospitalized patients: a cluster randomized trial. Ann Intern Med 2012;157:692-9. https://www.ncbi.nlm.nih.gov/pmc/articles/PMC3549269/. doi:10.7326/0003-4819-157-10-201211200-0000523165660
7 Barker AL, Morello RT, Wolfe R. 6-PACK programme to decrease fall injuries in acute hospitals: cluster randomised controlled trial. BMJ 2016;352:h6781. www.bmj.com/content/ 352/bmj.h6781. doi:10.1136/bmj.h678126813674

8 National Institute for Health and Care Excellence. March 2015. Falls in older people. https: //www.nice.org.uk/guidance/qs86/chapter/quality-statements.

9 Royal College of Physicians. NAIF audit report 2015. 8 Oct 2015. https://www.rcplondon. ac.uk/projects/outputs/naif-audit-report-2015.

10 Healey F, Lowe D, Darowski A. Falls prevention in hospitals and mental health units: an extended evaluation of the FallSafe quality improvement project. Age Ageing 2014;43:484-91. https://academic.oup.com/ageing/article/43/4/484/15519. doi:10.1093/ageing/aft19024321841

11 Cracknell A, Lovatt A, Winfield A. Huddle up for safer healthcare: how frontline teams can work together to improve patient safety. Future Hosp J 2016;3 (suppl 2):s31.http:// futurehospital.rcpjournal.org/content/3/Suppl_2/s31.extract.

Published by the BMJ Publishing Group Limited. For permission to use (where not already granted under a licence) please go to http://group.bmj.com/group/rights-licensing/ permissions 